\title{
Disease Development Following Infection of Tomato and Basil Foliage by Airborne Conidia of the Soilborne Pathogens Fusarium oxysporum f. sp. radicis-lycopersici and F. oxysporum f. sp. basilici
}

\author{
Y. Rekah, D. Shtienberg, and J. Katan
}

First and third authors: Department of Plant Pathology and Microbiology, The Hebrew University of Jerusalem, Faculty of Agricultural, Food and Environmental Quality Sciences, Rehovot 76100; and second author: Department of Plant Pathology, ARO, The Volcani Center, Bet Dagan 50250, Israel.

Accepted for publication 21 August 2000.

\begin{abstract}
Rekah, Y., Shtienberg, D., and Katan, J. 2000. Disease development following infection of tomato and basil foliage by airborne conidia of the soilborne pathogens Fusarium oxysporum f. sp. radicis-lycopersici and $F$. oxysporum f. sp. basilici. Phytopathology 90:1322-1329.

Fusarium oxysporum f. sp. radicis-lycopersici, the causal agent of Fusarium crown and root rot of tomato, and F. oxysporum f. sp. basilici, the causal agent of Fusarium wilt in basil, are soilborne pathogens capable of producing conspicuous masses of macroconidia along the stem. The role of the airborne propagules in the epidemics of the disease in tomato plants was studied. In the field, airborne propagules of $F$. oxysporum f. sp. radicis-lycopersici were trapped with a selective medium and their prevalence was determined. Plants grown in both covered and uncovered pots, detached from the field soil, and exposed to natural aer-

ial inoculum developed typical symptoms (82 to $87 \%$ diseased plants). The distribution of inoculum in the growth medium in the pots also indicated the occurrence of foliage infection. In greenhouse, foliage and root inoculations were carried out with both tomato and basil and their respective pathogens. Temperature and duration of high relative humidity affected rate of colonization of tomato, but not of basil, by the respective pathogens. Disease incidence in foliage-inoculated plants reached 75 to $100 \%$. In these plants, downward movement of the pathogens from the foliage to the crown and roots was observed. Wounding enhanced pathogen invasion and establishment in the foliage-inoculated plants. The sporulation of the two pathogens on stems, aerial dissemination, and foliage infection raise the need for foliage protection in addition to soil disinfestation, in the framework of an integrated disease management program.
\end{abstract}

Fusarium crown and root rot of tomato (Lycopersicon esculentum Miller), caused by Fusarium oxysporum (Schlecht.) f. sp. radicis-lycopersici (Jarvis \& Shoemaker), is an important disease worldwide. The pathogen produces conspicuous pinkish masses of macroconidia along the stem (9). F. oxysporum f. sp. basilici, the causal agent of Fusarium wilt and crown rot in basil (Ocimum basilicum L.), also produces a pale pink-orange macroconidia layer on the basil stem $(5,20)$.

Production of sporulation layer on the stem is not typical for diseases caused by $F$. oxysporum pathogens. However, in addition to these two pathogens, this phenomenon has been reported with F. oxysporum f. sp. lycopersici in tomato (10), F. oxysporum f. sp. cucumerinum in cucumber $(1,3), F$. oxysporum f. sp. radiciscucumerinum in cucumber (21), F. oxysporum f. sp. cyclaminis in cyclamen (23), $F$. oxysporum f. sp. perniciosum in mimosa $(13,19)$, and other Fusarium pathogens $(10)$. Air dissemination of macroconidia has been suggested to be responsible for rapid reinfestation of fumigated soils and disease outbreaks in tomato plants in greenhouses $(17,18)$. The aerial dissemination potential was quantified by trapping airborne macroconidia in tomato fields and greenhouses $(6,10,17,18)$ and in basil greenhouses $(5)$.

Reports on foliage infection by soilborne pathogens are not common. Uchida and Kadooka (20) suggested that F. oxysporum f. sp. basilici infects the above-ground parts of basil plants. They based their conclusion on the pattern of infection and on the occurrence of stem lesions in field plantings. Aerial spread has also been suggested for Verticillium spp. $(2,7,8)$. Verticillium conidia

Corresponding author: Y. Rekah; E-mail address: rekah@agri.huji.ac.il

Publication no. P-2000-0920-01R

(C) 2000 The American Phytopathological Society produced on wilting stems were reported as a possible source of inoculum dissemination and as the cause of infection in alfalfa (lucerne) plants $(7,8)$. A large number of airborne conidia were trapped in lucerne fields and penetration of the pathogen into the plants through wounded surfaces was suggested $(2,8)$. Discoloration has been reported to spread downward from the crown into the main root (8). However, direct inoculation of the foliage and observation of subsequent infections were not reported in these studies.

The epidemiological consequences of foliar infection by soilborne pathogens could be important. Soilborne pathogens are frequently considered to cause monocyclic diseases. Thus, the principal control strategy is aimed at reducing the amount of initial inoculum. However, if soilborne pathogen inoculum can disseminate in the air and infect host plants in the same growing season (as do polycyclic foliar pathogens), the disease control strategies should be reconsidered.

The objectives of this work were to (i) evaluate the prevalence of airborne propagules of $F$. oxysporum f. sp. radicis-lycopersici and their role in the epidemiology of crown and root rot disease in tomato fields; (ii) determine the effects of environmental factors on foliar infection of $F$. oxysporum $\mathrm{f}$. sp. radicis-lycopersici in tomato and $F$. oxysporum f. sp. basilici in basil; and (iii) study the dynamic progression of the two pathogens within the plant, following foliar or soil inoculation.

\section{MATERIALS AND METHODS}

Trapping airborne propagules in the field. Experiments were conducted at the Kikar Sedom Experimental Station in En Tamar, close to the Dead Sea, in the southeastern Israeli Desert, to evaluate the prevalence of air-disseminating propagules of $F$. oxy- 
sporum f. sp. radicis-lycopersici. This was carried out by trapping airborne conidia in petri dishes containing a modified peptonepentachloronitrobenzene Fusarium-selective medium (4). Propagules were trapped in the 1996, 1997, and 1998 seasons in naturally infested fields, planted in September to October each previous year (15). Trapping was performed on the planting date and every 10 to 14 days thereafter, until the end of the growing season. Plates (10 for each of 8 groups that were randomly scattered in the field) containing Fusarium-selective medium were placed on polyethylene sheets within the rows at ground level in the field plots. The plates were exposed between 9:00 and 11:00 a.m. and incubated at $27^{\circ} \mathrm{C}$ for 7 days. Colonies exhibiting F. oxysporum morphology were counted and samples were subcultured for pathogenicity testing (described below) to determine their forma specialis. The number of trapped colonies was used to calculate the number of landing propagules per square meter per hour in the field.

The quantity of macroconidia on the stem surface was determined toward the end of the experiments in 1997 and 1998 as described previously $(5,10)$. Stems covered with pinkish masses of Fusarium macroconidia (verified by microscopic examination) were cut into $1-\mathrm{cm}$ segments. The segments were placed in tubes with $5 \mathrm{ml}$ of sterile water. The tubes were shaken for $2 \mathrm{~min}$ in a vortex mixer, and conidia were counted directly in the suspension with a hemacytometer. Results were expressed as the number of conidia per centimeter of stem. Conidial viability was tested by spreading $0.1 \mathrm{ml}$ of the sampled suspension on Fusarium-selective medium and determining percent of germination after $15-\mathrm{h}$ incubation at $17^{\circ} \mathrm{C}$. There were eight stem segments (replicates) per sampling date. Sampling was repeated once each year.

Foliage infection of tomato plants under field conditions. The role of airborne propagules of $F$. oxysporum f. sp. radicislycopersici in crown and root rot disease in tomatoes was tested in 1998 and 1999. Tomato (cv. 5656) transplants, susceptible to the pathogen, were planted in 10-liter pots $(25 \mathrm{~cm}$ high) filled with tuff (volcanic ash, an artificial growth substrate). The tuff is originally quarried from mountain rocks that no plants can naturally grow on it. This substrate was defined as pathogen-free because control plants that were grown on it (using fertilizers) did not show any disease symptoms and no pathogens could be isolated from their roots. Furthermore, in 50 samples of tuff plated on Fusarium-selective medium, no Fusarium colonies were detected. Planting dates were in the last week of September in 1997 and 1998 for the corresponding 1998 and 1999 seasons. The pots were placed on wooden boards laid on plastic mulch spread on the soil, in order to exclude the possibility of pathogen's spreading from the soil to the growth medium and colonizing the plants through their roots. Each experiment consisted of two treatments. In the first, plants were grown in uncovered pots allowing aerial propagules of F. oxysporum f. sp. radicis-lycopersici to fall on either the foliage or the growth substrate. In the second treatment, plants were grown in pots in which the growth substrate was covered with plastic mulch, allowing only the foliage to be exposed to possible aerial inoculation. Accordingly, infestation of the growth medium by the pathogen and infection of the plants through their roots was possible only in the first treatment. There were four replicates per treatment, 20 pots per replicate, arranged in randomized complete blocks. The plants were irrigated via a dripirrigation system that was placed before covering the pots and maintained according to the recommendations of the Extension Service in that region. The plants were monitored periodically for symptoms of Fusarium crown rot. A plant was considered diseased if it exhibited typical irreversible wilt symptoms accompanied by brown necrosis on the crown and vascular discoloration on the lower stem (9). Following the onset of the disease, disease was assessed every 2 to 3 weeks until the end of the season. Samples of roots and crowns of diseased plants were taken for isolation and subsequent pathogenicity testing to confirm the presence of $F$. oxysporum f. sp. radicis-lycopersici. Disease incidence (the proportion of plants displaying Fusarium crown rot out of the total number of plants in the replicate) was calculated for each sampling date.

The inoculum density of $F$. oxysporum f. sp. radicis-lycopersici in the growth medium of covered and uncovered pots at the time of disease onset was determined by taking samples from the upper ( 0 to $5 \mathrm{~cm}$ ), middle (10 to $15 \mathrm{~cm}$ ), and lower $(20$ to $25 \mathrm{~cm}$ ) layers. In each sample, the number of CFU of $F$. oxysporum per gram of soil was determined by a soil-dilution method $(4,5)$. Representative colonies were taken for pathogenicity tests (described below) for identification of the pathogen.

Inoculation experiments in the greenhouse. Two sets of experiments were carried out with $F$. oxysporum f. sp. radicislycopersici and tomatoes and with $F$. oxysporum f. sp. basilici and basil plants. Tomato transplants (cv. 5656) were planted in pots (one plant per pot) filled with Rehovot sandy soil (3.8\% clay, $0.0 \%$ silt, $96.2 \%$ sand, and $0.4 \%$ organic matter; $\mathrm{pH}$ 6.9). The soil was free of $F$. oxysporum f. sp. radicis-lycopersici or other known pathogens. Plants grown in this soil as controls did not show disease symptoms, and no pathogen could be isolated from their roots. Two weeks after planting, plants were inoculated with the desired concentration of macroconidial suspension. Macroconidia for inoculation was prepared as follows. Dry stems and crowns of diseased tomato plants, covered with masses of Fusarium conidia (verified by microscopic examination) were cut into $1-\mathrm{cm}$ segments and shaken in $5 \mathrm{ml}$ of water with a vortex mixer for $2 \mathrm{~min}$. The resulting conidial suspension was counted by hemacytometer and adjusted to the desired concentration by dilution. Plants were inoculated via the soil by spreading $10 \mathrm{ml}$ of a spore suspension containing $10^{2}$ or $10^{4}$ macroconidia per $\mathrm{ml}$ on the soil surface around the plants. In a second experiment, a concentration of $10^{3}$ macroconidia per $\mathrm{ml}$ was used. Plant foliage was inoculated by spraying the above-ground parts of the plants to runoff with spore suspension containing $10^{5}$ or $10^{6}$ macroconidia per $\mathrm{ml}$. To avoid infestation of the soil during the aerial inoculation, the soil was covered with a polyethylene sheet that was overlaid with a 1-cm thick Acrilan sheet. These sheets were examined for the presence of $F$. oxysporum colonies at the end of the experiments. In addition, a test examining the possibility of contamination through the sheets during foliage inoculation was carried out. Petri dishes containing Fusarium-selective medium were covered with polyethylene sheet that was overlaid with a 1-cm thick Acrilan sheet, as for the pots in the greenhouse. The covered dishes were sprayed as the plants in the greenhouse, and were then incubated at $27^{\circ} \mathrm{C}$ for 5 days and checked for the presence of Fusarium colonies. No Fusarium colonies developed on the dishes. To avoid subsequent wash off of the macroconidia from the foliage to the growth medium, plants were irrigated only by drip-irrigation. The drip-irrigation system (Netafim, Irrigation Equipment and Drip Systems, Kibbutz Hazerim, Israel) was installed before covering the pots and before inoculating the plants foliage. The irrigation was controlled by an irrigation computer Miracle 6 (Netafim Irrigation Equipment and Drip Systems). The role of wounding on foliar infection was tested by cutting off the lowest leaf $(\approx 7 \mathrm{~cm}$ above ground) of some of the plants before inoculation. Nonwounded plants were inoculated and kept under the same conditions for comparison. Inoculated plants were covered with polyethylene bags for 24 or $48 \mathrm{~h}$ to maintain high relative humidity. Plants were transferred after inoculation to greenhouse cabins at temperatures of 22 or $27^{\circ} \mathrm{C}$. In the second experiment, plants were maintained at high relative humidity for $24 \mathrm{~h}$ at $22^{\circ} \mathrm{C}$. Each treatment consisted of four small (1.5-liter) pots and eight large (7-liter) pots (replicates), arranged in completely randomized design.

Progress of $F$. oxysporum f. sp. radicis-lycopersici in plant tissue was determined for the plants inoculated through the soil and in wounded and nonwounded plants inoculated through their foliage. Samples were taken from the roots, the crown, and along the 
stems at 10 and $20 \mathrm{~cm}$ above ground, 14, 49, and 149 days after inoculation (end of the experiment). Each sample was cut into $0.5-\mathrm{cm}$ segments and was surface-sterilized with $\mathrm{NaOCl}(1 \%)$ for $1 \mathrm{~min}$ and rinsed twice in sterile water. Each segment was cut into four pieces and placed on Fusarium-selective medium. Plates were incubated in the dark at $27^{\circ} \mathrm{C}$ for 5 to 7 days and colonies of F. oxysporum were identified morphologically. The identity of the forma specialis of representative isolates from different plants was confirmed by pathogenicity tests (described below). Colonization frequency was determined as the percentage of segments colonized by $F$. oxysporum $\mathrm{f}$. sp. radicis-lycopersici from the total number of plant segments assessed.

Progression of the pathogen from inoculated leaflets through the secondary petioles to the main petioles and the stem was examined in artificially inoculated plants. Drops of a $10^{6}$ macroconidia per $\mathrm{ml}$ suspension were placed on leaflets of tomato plants (cv. 5656). At 9, 15, and 30 days after inoculation, inoculated leaflets and the secondary and main petioles were cut into $1-\mathrm{cm}$ segments and surface-sterilized with $\mathrm{NaOCl}(1 \%)$ for $1 \mathrm{~min}$ and rinsed twice in sterile water. Each segment was placed on Fusariumselective medium. Plates were incubated in the dark at $27^{\circ} \mathrm{C}$ for 5 to 7 days and colonies of $F$. oxysporum were identified morphologically. The identity of the pathogen isolated was confirmed by pathogenicity tests (described below). Forty-five days after inoculation the stems of these tomato plants were cut into $1-\mathrm{cm}$ pieces and examined for the presence of the pathogen as described below.

In general, the $F$. oxysporum f. sp. basilici greenhouse experiments in basil were similar to those conducted for $F$. oxysporum $\mathrm{f}$. sp. radicis-lycopersici in tomato. The principal differences are specified below. Basil transplants (cv. Chen) were planted in

TABLE 1. Airborne propagules of Fusarium oxysporum f. sp. radicislycopersici trapped in tomato fields and the incidence of crown and root rot disease during three growing seasons

\begin{tabular}{lccc}
\hline Season & Sampling date & Propagules per $\mathrm{m}^{2} / \mathrm{h}^{\mathrm{b}}$ & Disease incidence $(\%)^{\mathrm{c}}$ \\
\hline 1996 & 0 & 0 & 0 \\
& 24 & 0 & 0 \\
& 52 & 0 & 0 \\
& 66 & 0 & $0.7 \pm 0.9$ \\
& 80 & 2.0 & $5.4 \pm 3.6$ \\
& 99 & 9.8 & $31.9 \pm 9.2$ \\
& 113 & 10.8 & $54.4 \pm 8.2$ \\
& 129 & 48.2 & $86.6 \pm 4.6$ \\
& 150 & 2.9 & $93.7 \pm 3.7$ \\
1997 & 173 & 1.0 & $98.5 \pm 2.1$ \\
& 0 & 0 & 0 \\
& 42 & 0 & 0 \\
& 63 & 0 & 0.2 \\
& 77 & 1.0 & $6.1 \pm 1.9$ \\
& 91 & 0 & $23.7 \pm 7.6$ \\
& 105 & 2.0 & $44.7 \pm 12.2$ \\
& 119 & 1.0 & $68.7 \pm 8.5$ \\
& 135 & 3.9 & $84.9 \pm 4.2$ \\
& 149 & 0 & $94.6 \pm 2.1$ \\
& 169 & 0 & $95.6 \pm 1.7$ \\
& 0 & 0 & 0 \\
& 73 & 260.3 & $1.9 \pm 0.8$ \\
& 95 & 22.8 & $32.9 \pm 5.3$ \\
& 122 & 12.6 & $81.7 \pm 3.2$ \\
& 149 & 0 & $84.6 \pm 8.1$ \\
\hline
\end{tabular}

a Sampling date refers to days after planting. Planting dates were 2 October 1995 for the 1996 season, 6 October 1996 for the 1997 season, and 28 September 1997 for the 1998 season.

${ }^{b}$ The number of trapped propagules was calculated from the number of colonies that developed on 9-mm petri dishes containing Fusariumselective medium. The plates were exposed in the field for $2 \mathrm{~h}$ in the morning. Approximately $97 \%$ of the propagules were determined pathogenic.

${ }^{c}$ Disease incidence ( \pm standard error) was calculated as the proportion of plants displaying Fusarium crown rot out of the total number of plants in the experimental plot. 1.5-liter pots containing Rehovot sandy soil. Two weeks after planting, plants were cut off at a height of $15 \mathrm{~cm}$ (as practiced in commercial basil cultivation) and inoculated with $F$. oxysporum f. sp. basilici. For soil inoculation, $5 \mathrm{ml}$ of a spore suspension containing $10^{3}$ macroconidia per $\mathrm{ml}$ was used. For foliar inoculation, plants were sprayed to runoff with spore suspension containing $10^{3}$ or $10^{4}$ macroconidia per ml. Inoculated plants were covered with polyethylene bags for 12 or $24 \mathrm{~h}$ to maintain high relative humidity. In a second experiment, plants were maintained under high relative humidity for $12 \mathrm{~h}$. Plants were grown after inoculation in a greenhouse at $27^{\circ} \mathrm{C}$. Dynamics of the pathogen's progress within the organs of basil plant was determined on samples taken from roots, crown, and the stem at $20 \mathrm{~cm}$ above ground. Each treatment consisted of 6 to 12 pots (replicates) arranged in completely randomized design. Two controls were included in the experiments: 10 noninoculated plants were kept in the same greenhouse as the inoculated plants and 10 noninoculated plants were grown in a different greenhouse without inoculated plants, under the same conditions. The experiment was repeated once.

At the end of the greenhouse experiments, disease incidence was calculated as the proportion of plants displaying disease symptoms out of the total number of plants in the corresponding experiment. Tomato plants were considered diseased if discoloration of the xylem was noticed or if the plant died, sometimes accompanied by production of pinkish macroconidia on the stem. Basil plants were considered diseased if discoloration and wilt of stems or the whole plant, and sometimes macroconidia production on the stems was detected.

Pathogenicity tests. Pathogenicity tests were used to determine the forma specialis of the colonies of $F$. oxysporum trapped from the air, isolated from soil or from different organs of tomato or basil plants. The tests were essential as previously described $(5,11)$. Colonies were subcultured on Czapeck-Dox medium and incubated in the dark at $27^{\circ} \mathrm{C}$ for 9 days. The content of each petri dish was macerated with $60 \mathrm{ml}$ of water to prepare inoculum suspension. The roots of 16-day-old tomato seedlings (cv. Rehovot 13) or 30-day-old basil seedlings (cv. Chen) were inoculated with a spore suspension of the tested isolate by dipping their roots for 2 min in the inoculum suspension. Seedlings were then transplanted into pots (five seedlings per pot) filled with Rehovot sandy soil. The inoculated tomato seedlings were maintained in a greenhouse at $22^{\circ} \mathrm{C}$ for 14 days, and basil seedlings were main-

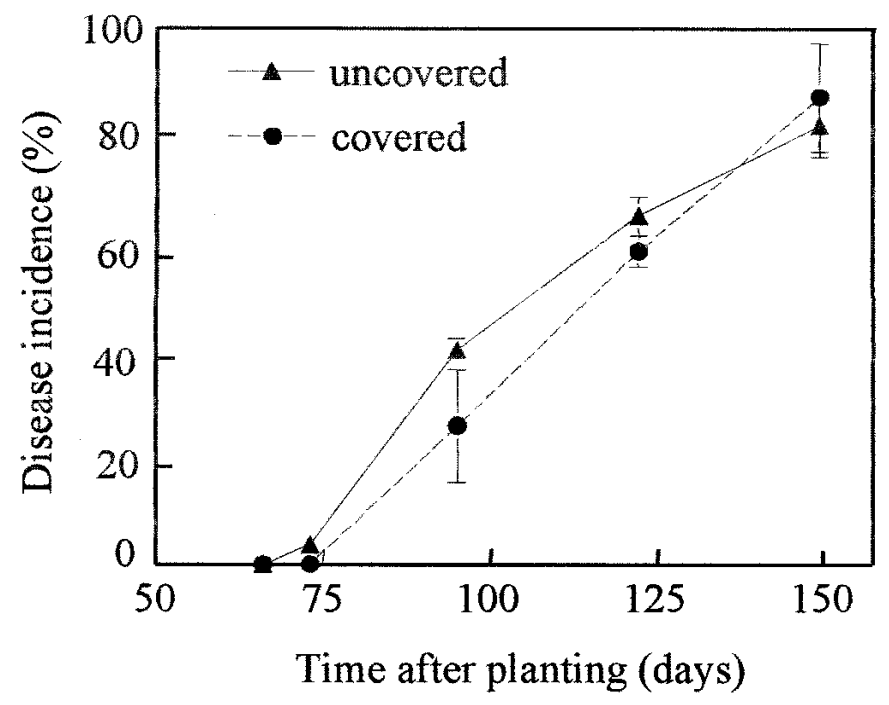

Fig. 1. Progression of Fusarium crown and root rot disease, caused by Fusarium oxysporum f. sp. radicis-lycopersici, in tomato plants grown in covered and uncovered pots. The pots were isolated from the ground and were placed in a commercial experimental field in 1998. Vertical bars represent standard error. 
tained in a greenhouse at $27^{\circ} \mathrm{C}$ for 20 days. The isolates were identified as $F$. oxysporum f. sp. radicis-lycopersici or $F$. oxysporum f. sp. basilici if at least three out of the five seedlings in each pot became diseased. Noninoculated seedlings maintained under the same conditions served as controls and did not show any disease symptoms in any of the tests. Pathogenicity tests were performed with 90 to $95 \%$ of the $F$. oxysporum-like colonies trapped from the air and with $30 \%$ of the isolates taken from inoculated tomato and basil plants from the greenhouse experiments.

\section{RESULTS}

Trapping airborne propagules in the field. Airborne propagules of $F$. oxysporum f. sp. radicis-lycopersici were trapped in naturally infested fields during the three seasons of the study (Table 1). Most (97\%) of the trapped isolates were pathogenic to tomato seedlings and, therefore, these trapped colonies were considered to be F. oxysporum f. sp. radicis-lycopersici. Propagules were not trapped before the date of disease onset and the number of propagules recovered from the air was not related to the incidence of disease in the fields during the three seasons of the study. The number of propagules trapped ranged from 0 to $260 / \mathrm{m}^{2} / \mathrm{h}$. The number of conidia counted on the surface of stems sampled from diseased plants ranged from $6.2 \times 10^{7}$ to $4 \times 10^{8}$ per centimeter of stem. Viability of the macroconidia was above $95 \%$. The typical length of the sporulating part of the stem was $5 \mathrm{~cm}$ per plant, giving a calculated number of conidia per diseased plant ranging from $3.1 \times 10^{8}$ to $2 \times 10^{9}$.

Foliage infection of tomato plants under field conditions. Plants that were exposed to natural aerial infection under field conditions and were grown in both covered and uncovered pots exhibited typical disease symptoms. Disease progression in the uncovered and covered pots was similar in 1998, although a slight delay was observed in the covered pots in the first stages of the epidemic (Fig. 1). Final disease incidence in the pots was $81.7 \%$ for the uncovered pots and $87.4 \%$ for the covered pots. In 1999 , disease incidence was lower and at the end of the season it was 60 and $48.7 \%$ for the two treatments, respectively.

The density of $F$. oxysporum f. sp. radicis-lycopersici in covered and uncovered pots. Inoculum density in uncovered pots was 10- to 100-fold greater than that observed in the covered pots (Fig. 2). Differences among the pots and their different layers in each treatment were insignificant. Similar results pertaining to inoculum densities of the pathogen in the soil were also obtained in 1999 (data not shown).

Inoculation experiments in the greenhouse. Results regarding tomato and basil colonization by the pathogens exhibited similar trends, although some differences were apparent between the two pathosystems. Irrespective of the factor that was tested, the colonization of tomato roots and crown was higher than colonization of stem by $F$. oxysporum f. sp. radicis-lycopersici (Fig. 3A through C). With basil, F. oxysporum f. sp. basilici colonized all plant organs similarly (Fig. 3D and E). Temperature affected the rate of tomato stem colonization by $F$. oxysporum f. sp. radicislycopersici but not the colonization of the roots or crown. A high (50 to $94 \%$ ) rate of colonization was observed in all plant organs of tomato grown at $27^{\circ} \mathrm{C}$. Colonization rates along tomato stem were lower at $22^{\circ} \mathrm{C}$ than at $27^{\circ} \mathrm{C}$ (Fig. 3A).

The period of time that plants were maintained under conditions of high relative humidity after foliar inoculation did not affect the rate of colonization of basil organs but did affect colonization of tomato crown (Fig. 3B and D). The concentrations of macroconidia used for foliar inoculation affected the colonization of tomato stems and basil roots. The effect on the colonization of other organs was similar (Fig. 3C and E).

Colonization of tomato plants by $F$. oxysporum $\mathrm{f}$. sp. radicislycopersici was related to the site of inoculation (soil vs. foliage) and to the existence of wounds. Following soil inoculation, roots and crown were colonized earlier, and the rate of colonization increased faster in these organs than in the stems (Fig. 4A). In contrast, differences in colonization among plant organs were less apparent following foliar inoculation. Colonization rates in the roots and crown of foliage-inoculated plants were slower than those observed in soil-inoculated plants. Nevertheless, at the end of the experiment, 75 to $90 \%$ of root and crown segments of the foliage-inoculated plants were infected with the pathogen. The rate of stem colonization was similar in soil- and foliage-inoculated plants (Fig. 4A and B). Wounding increased colonization in stem part adjacent to the wounding site (10 $\mathrm{cm}$ above ground). It resulted in rapid progress of the pathogen to the roots and crown, but colonization rate above the site of wounding was less affected (Fig. 4C).

In further studies, downward movement of $F$. oxysporum $\mathrm{f}$. sp. radicis-lycopersici from tomato leaflets through secondary petioles to the main petioles and stem was observed. The pathogen was detected in all leaflets and in 2 out of 7 main petioles 9 days after inoculation; in 4 out of 11 main petioles 15 days after inoculation; and in 6 out of 13 main petioles 30 days after inoculation. Nine days after inoculation, the pathogen was detected in the secondary petioles and $2 \mathrm{~cm}$ downward in the main petiole. As time progressed (15 and 30 days after inoculation), the pathogen was detected in the secondary petioles and at a distance of 5 to $7 \mathrm{~cm}$ downward in the main petioles toward the stem. The pathogen was also detected at the stem 15 days after inoculation, $2 \mathrm{~cm}$ below the main petiole of an inoculated leaf.

Colonization of basil plants by F. oxysporum f. sp. basilici inoculated through the soil was very rapid. Within 30 days following inoculation, colonization of all plant organs (including stems at a height of $20 \mathrm{~cm}$ above ground) was $100 \%$ (Fig. 5A). Colonization of the plants by the pathogen in foliage-inoculated plants was lower. Thirty days after inoculation, colonization of the pathogen in the stem adjacent to the wound site and in the crown was higher than in the roots (50 and $37.5 \%$, respectively). At that time, the pathogen was not recovered from the new shoots located $10 \mathrm{~cm}$ above the wound site (20 cm above ground) (Fig. 5A). Six weeks later, the pathogen had invaded all plant organs and colonization rate was 70 to $90 \%$, even in the organ located $20 \mathrm{~cm}$ above ground (Fig. 5B). Plants that were not wounded were colonized by the pathogen at similar rates.

The incidence of disease caused by foliar and soil inoculation was determined in the greenhouse at the end of the experiments.

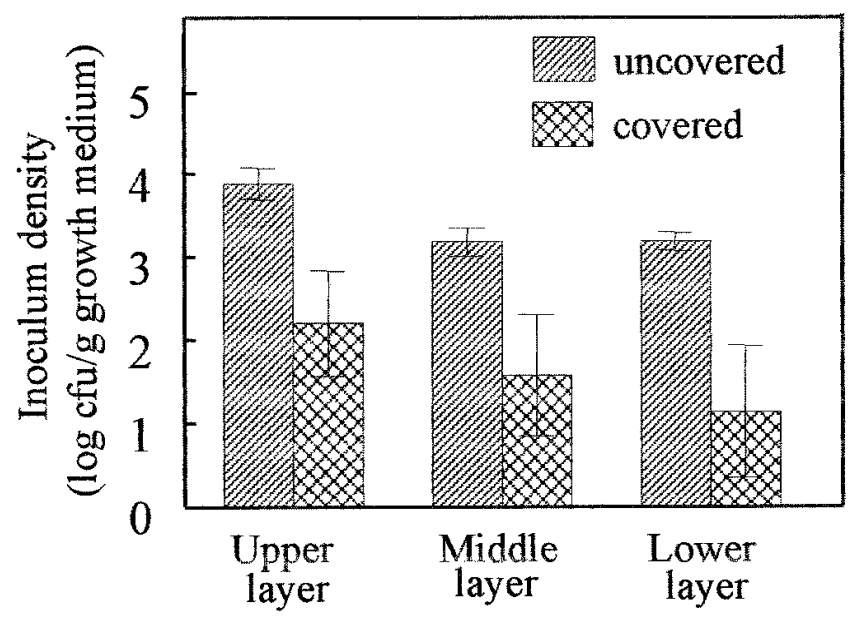

Fig. 2. Inoculum density of Fusarium oxysporum f. sp. radicis-lycopersici in three layers of covered or uncovered pots, filled with tuff (volcanic ash, an artificial growth substrate) in the 1998 season. The pots were isolated from the ground and were placed in a commercial experimental field. Inoculum density was assessed at disease onset in tomato plants. Vertical bars represent the standard error. 
Inoculation of tomato foliage resulted in a high incidence of crown and root rot (75 to $83 \%$ ) at both concentrations of macroconidia used (Fig. 6A). Disease incidence in plants inoculated via the soil was similarly high when the higher amount of inoculum $\left(10^{4}\right.$ macroconidia per $\left.\mathrm{ml}\right)$ was used, but significantly lower when a concentration of $10^{2}$ macroconidia per ml was used for inoculation. Noninoculated (control) tomato plants did not show disease symptoms and were not infected by the pathogen (determined by isolation on Fusarium-selective medium). For basil, disease incidence was high (75 to 100\%) in both foliage- and soil-inoculated plants (Fig. 6B). Half of the noninoculated basil plants that were placed near the inoculated plants in the same greenhouse exhibited disease symptoms by the end of the experiment. Noninoculated basil (control) plants that were placed in another greenhouse did not show any disease symptoms and were not infected.

At the end of the greenhouse experiments in tomato and in basil plants, no $F$. oxysporum colonies could be detected on the top or bottom of the polyethylene sheet or on the bottom of the Acrilan sheet that covered the pots during the experiments.

\section{DISCUSSION}

Airborne propagules of $F$. oxysporum f. sp. radicis-lycopersici were present in the field and were capable of disseminating the pathogen from one site to another, as had already been shown by other researchers $(5,10,17,18)$, and also of infecting plants and causing disease in the growing season. This was verified both in the field and by artificial inoculation of the foliage of tomato and basil plants. Thus, both types of inocula, soil and aerial, may be sources for the two diseases. This may increase the chance of a disease outbreak and intensify the polycyclic nature of these soilborne pathogens. According to our research, this is the first report of foliage infection by soilborne $F$. oxysporum pathogens. The epidemiological consequences and the relative importance of aerial vs. soil propagules under diverse conditions have yet to be studied.

Stems of diseased plants in the field produce heavy masses of pathogenic conidia that appear to be the source of the airborne propagules. The number of macroconidia produced by $F$. oxysporum f. sp. radicis-lycopersici on stems of tomato plants dis-

\section{Tomato}
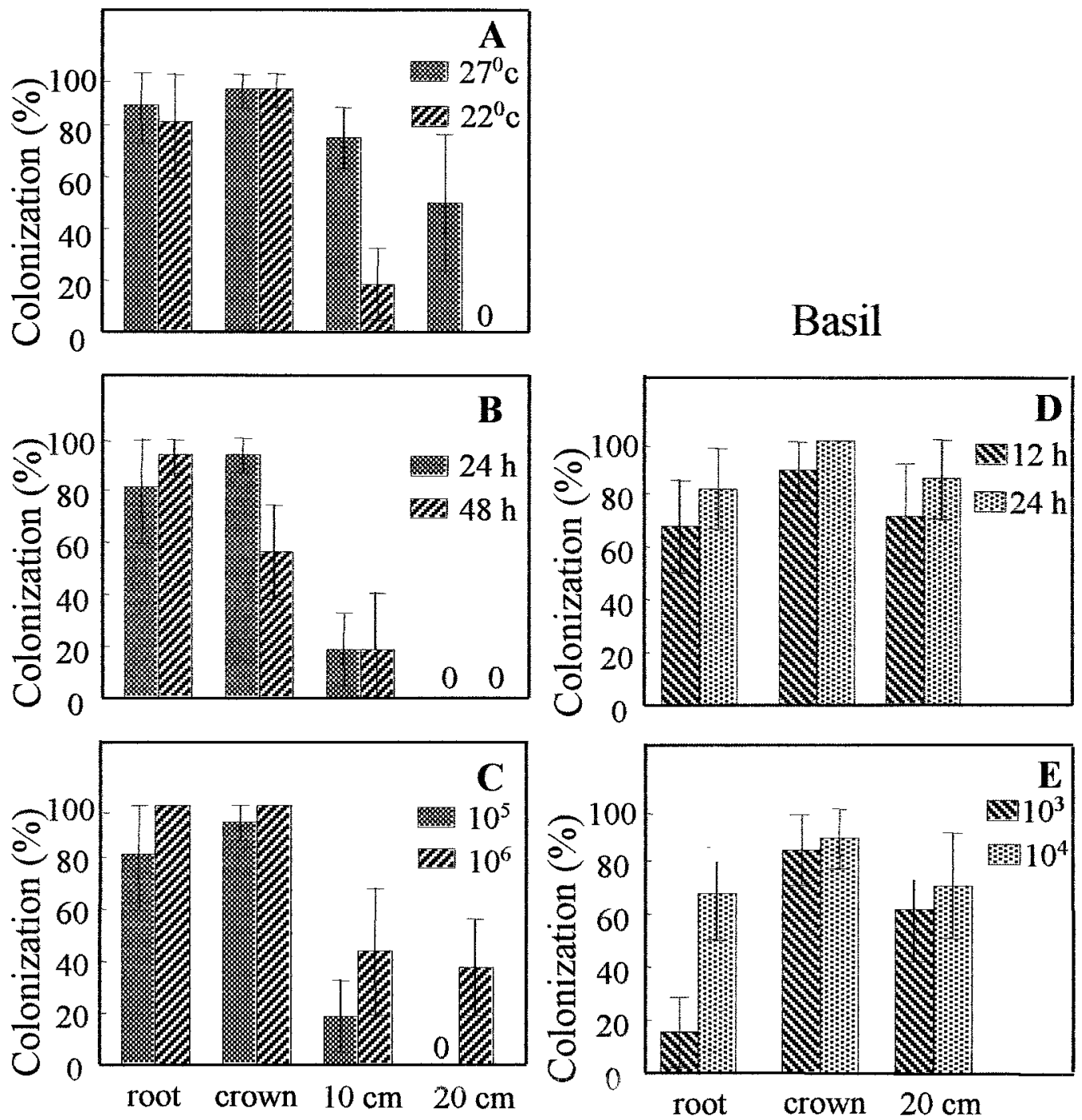

Fig. 3. A, Effects of temperature, $\mathbf{B}$ and $\mathbf{D}$, duration of high relative humidity after inoculation, and $\mathbf{C}$ and $\mathbf{E}$, the concentration of inoculum used on colonization rate in tomato plants by Fusarium oxysporum f. sp. radicis-lycopersici and in basil plants by F. oxysporum f. sp. basilici. Colonization of the pathogen was assessed in the root, crown, and along the stem, 10 and $20 \mathrm{~cm}$ above the soil surface. Colonization rate is expressed as percentage of plant segments colonized by the pathogen at the end of the experiments (150 and 73 days after inoculation for tomato and basil plants, respectively). Tomato plants were inoculated with $10^{5}$ macroconidia per ml suspension and maintained in high relative humidity for $24 \mathrm{~h}$ at $22^{\circ} \mathrm{C}$, unless otherwise indicated. Basil plants were inoculated with $10^{4}$ macroconidia per $\mathrm{ml}$ suspension and maintained for $12 \mathrm{~h}$ in high relative humidity at $27^{\circ} \mathrm{C}$, unless otherwise indicated. Vertical bars represent the standard error. 
playing crown and root rot symptoms $\left(6.2 \times 10^{7}\right.$ to $4 \times 10^{8}$ propagules per $\mathrm{cm}$ of stem) was in the range of those produced on basil stems by $F$. oxysporum f. sp. basilici $\left(2.2 \times 10^{6}\right.$ to $4.4 \times 10^{7}$ propagules per $\mathrm{cm}$ of stem) (5) and on tomato stems by $F$. oxysporum f. sp. lycopersici $\left(0.7 \times 10^{6}\right.$ to $1.4 \times 10^{8}$ propagules per centimeter of stem) (10).

Airborne propagules of $F$. oxysporum f. sp. radicis-lycopersici were trapped during three growing seasons in tomato fields (Table 1) and their level was comparable to those reported by Rowe and Farely (17) for this pathogen (equivalent to 1.3 to 1.6 propagules per $\mathrm{m}^{2}$ every $2 \mathrm{~h}$ ). The number of trapped airborne propagules was also in the range reported for $F$. oxysporum f. sp. lycopersici (10), but lower than that reported for $F$. oxysporum $\mathrm{f}$.
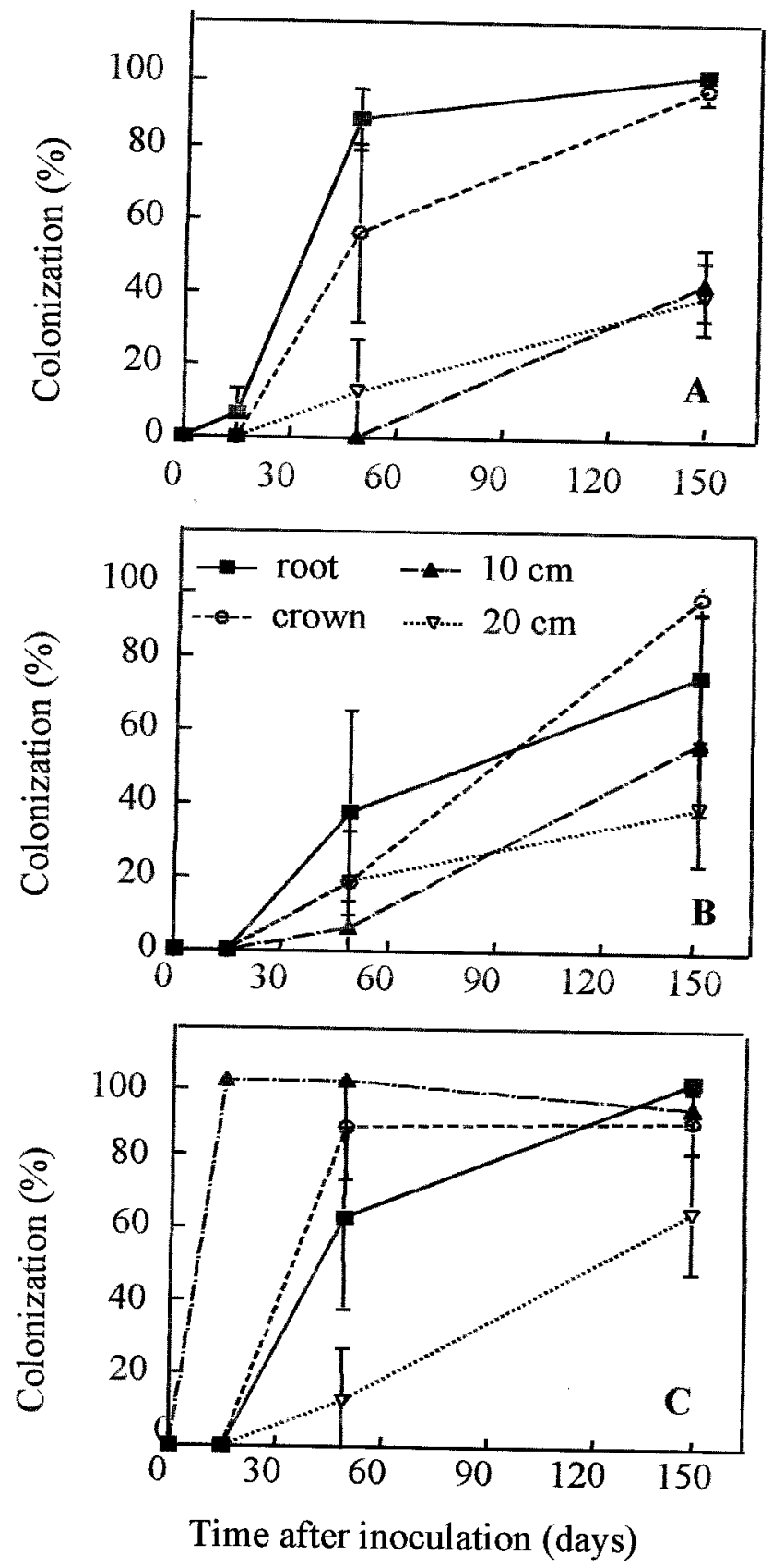

Fig. 4. Colonization of tomato plant organs by Fusarium oxysporum f. sp. radicis-lycopersici following soil or foliage inoculation. Colonization of the pathogen was assessed in the root, crown, and along the stem, 10 and $20 \mathrm{~cm}$ above the soil surface. Inoculum was applied to $\mathbf{A}$, soil, or $\mathbf{B}$, sprayed on the foliage of nonwounded, or $\mathbf{C}$, wounded plants. Concentration of the suspension used for soil inoculation was $10^{3}$ macroconidia per $\mathrm{ml}$. The foliage was inoculated with $10^{5}$ macroconidia per $\mathrm{ml}$ and plants were maintained for $24 \mathrm{~h}$ at high relative humidity at $22^{\circ} \mathrm{C}$. Vertical bars represent the standard error. sp. basilici (5). If there is a deposit of propagules, even during a small fraction of the season, the cumulative amount of trapped propagules is likely to be very high over the entire season. No correlation was observed between disease incidence and the number of trapped propagules. These findings are different from those reported with $F$. oxysporum f. sp. basilici in basil greenhouses (5) and can be explained by the fact that trapping in our case was carried out in open areas where the propagules could be disseminated over greater distances by winds.

Tomato plants grown in pots were used as living traps to test the ability of airborne propagules of $F$. oxysporum $\mathrm{f}$. sp. radicislycopersici to infect plants and cause disease under natural conditions. In uncovered pots, infection could occur either through the roots (following soil infestation) or by direct penetration of the foliage by the pathogen. In contrast, in covered pots only the latter mechanism was possible. A nonsignificant difference in disease progress between the plants in the covered and the uncovered pots was observed during the 1998 season (Fig. 1), and by the end of the experiment, disease incidence through foliar infection was high (82 to $87 \%)$. This suggests that the aerial-disseminated propagules play an important role in the epidemic development. At disease onset, the average inoculum density in the growth medium of uncovered pots (Fig. 2) reached a level similar to that in the root zone of plants grown in the open field (14), indicating that the pathogen had proliferated in the root zone. The approxi-
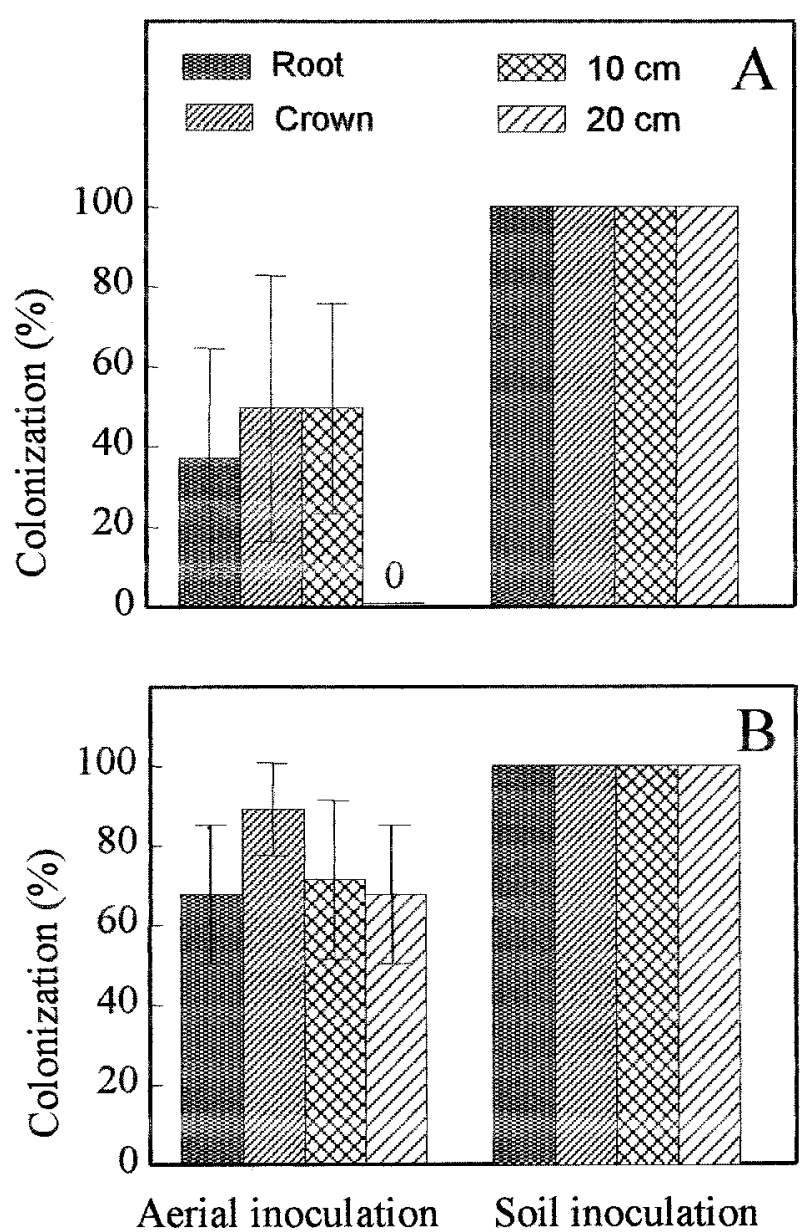

Fig. 5. Colonization of basil plants following soil or foliage inoculation at $\mathbf{A}$, 30 and $\mathbf{B}, 76$ days after inoculation. Colonization by Fusarium oxysporum $\mathrm{f}$. sp. radicis-lycopersici was assessed in the root, crown, and along the stem, 10 and $20 \mathrm{~cm}$ above the soil surface. Inoculum was applied to the soil or sprayed on the foliage of cut-off plants, $15 \mathrm{~cm}$ in height. Concentrations of the suspension used for soil inoculation was $10^{2}$ macroconidia per $\mathrm{ml}$. The foliage was inoculated with $10^{4}$ macroconidia per $\mathrm{ml}$ and the plants were maintained for $12 \mathrm{~h}$ at high relative humidity. All plants were grown in greenhouse cabins at $27^{\circ} \mathrm{C}$. Vertical bars represent the standard error. 
mate 100-fold lower inoculum density of the pathogen in the growth medium of covered pots may be due to the fact that these plants were diseased via aerial infection, and released propagules from their decayed or broken roots to the growth substrate. Similar phenomenon has been reported for V. albo-atrum $(12,16)$.

In tomato plants, colonization rates along the stem were lower in all treatments than those recorded in the roots and crown. These findings are in accordance with the common observation that symptoms of Fusarium crown and root rot of tomatoes are limited to the lower parts of the stem (9). Colonization rates along the stem were influenced by temperature and inoculum concentration (Fig. 3A and $\mathrm{C}$ ) and that of crown was affected by duration of high relative humidity (Fig. $3 \mathrm{~B}$ ). At $27^{\circ} \mathrm{C}$ the pathogen progressed higher along the stem than at $22^{\circ} \mathrm{C}$ (Fig. 3A). Higher colonization rate along the tomato stem was observed when using high inoculum level (Fig. 3C). Like wilt and vascular disease caused by $F$. oxysporum f. sp. lycopersici in tomatoes (22), F. oxysporum f. sp. basilici in basil induces xylem discoloration throughout the upper stem (5), and the pathogen was isolated from all stem parts (Fig. 3D and $\mathrm{E}$ and 5).

Progress of $F$. oxysporum f. sp. radicis-lycopersici within the plant tissue was affected by the site of pathogen penetration. As expected, the roots and crown of tomato plants that were inoculated via the soil were colonized by the pathogen earlier and at higher rates than the above-ground organs (Fig. 4A). When inoculum was applied to nonwounded foliage, colonization of all
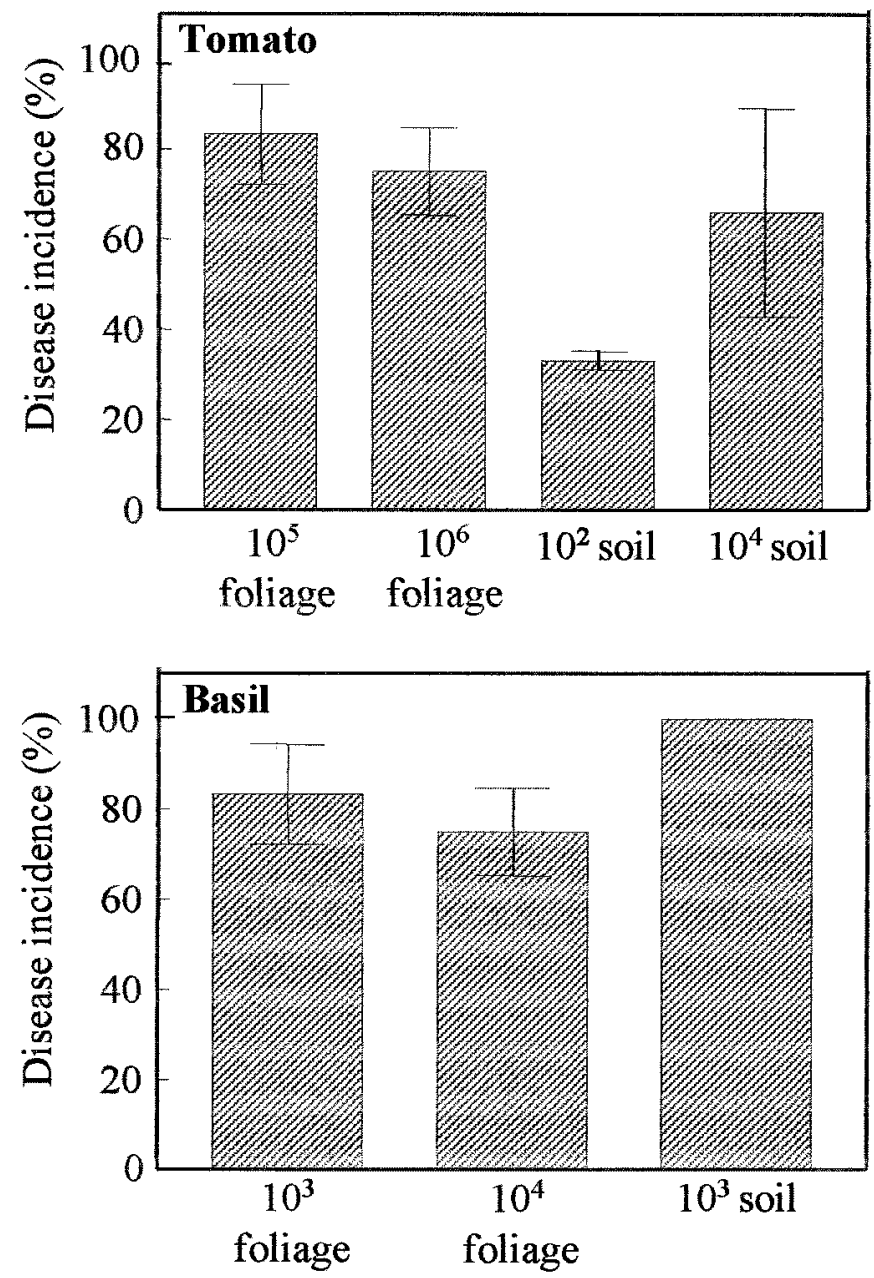

Fig. 6. Incidence of Fusarium crown and root rot (caused by Fusarium oxysporum f. sp. radicis-lycopersici) in tomato plants and of Fusarium wilt (caused by $F$. oxysporum $\mathrm{f}$. sp. basilici) in basil plants following soil or foliar inoculation with inoculum concentrations Assessments were made at the end of the experiments, 150 and 73 days after inoculation of tomato and basil plants, respectively. Vertical bars represent the standard error. plant organs was delayed and detectable only 49 days after inoculation (Fig. 4B). It was also demonstrated, by isolation from different plant's organs, that the pathogen is capable of penetrating and infecting the plant by moving from an inoculated leaflet via the petioles down to the stem. A wound in the tomato foliage (a phenomenon that is common under field conditions) enhanced plant invasion by the pathogen. When foliage-wounded plants were inoculated with the pathogen, colonization at the wound site was rapid. As time progressed, the pathogen spread more downward, from the wound site toward the crown and roots, than upward toward the upper part of the stem (Fig. 4C). Again, this agrees with the observation that $F$. oxysporum f. sp. radicislycopersici is not a vascular pathogen but rather a rot-inducing one (9). The sites that disease symptoms were most apparent, the roots and crown of tomato plants, were the most colonized by the pathogen. Colonization of basil plants by $F$. oxysporum $\mathrm{f}$. sp. basilici was similar to that of tomatoes by $F$. oxysporum f. sp. radicis-lycopersici (i.e., preferred movement toward the roots and crown with a high colonization rate of these organs). Nevertheless, colonization of basil stems was also high (Fig. 5), reflecting its characteristic as a pathogen inducing both crown rot and vascular wilt (5).

Symptoms of Fusarium crown and root rot in tomatoes, including macroconidial production on stems, have been observed in the field not earlier than 63 days after planting $(14,15)$. Furthermore, if one disease cycle lasts 2 months, foliage-infected plants may not always exhibit disease symptoms within the growing season. However, even if disease is not observed in plants that were aerially infected from neighboring plants, they may still be colonized by the pathogen and may infect adjacent plants by root-to-root contact (15) or increase the inoculum in the soil for the next season. Disease symptoms in basil plants were apparent 5 weeks after inoculation. Basil production in Israel lasts 5 to 6 months. This suggests that in contrast to tomatoes, several overlapping cycles of disease may develop in the basil crop in the same growing season. Indeed, $50 \%$ of the noninoculated basil plants that were placed in the greenhouse with the inoculated plants became diseased.

In this study, we demonstrated the diversity of means of dissemination and infection of two soilborne pathogens. Soilborne pathogens that also have characteristics of foliar pathogens are especially difficult to manage. Preplanting soil disinfestation may not be sufficient to manage such pathogens. This situation calls for the development of a holistic, integrated approach to dealing with all inoculum sources and means of infection before, during, and after planting $(5,10)$. Potential means of pathogen and disease management include measures that suppress conidial production on diseased plants (for example, site chemical or biological treatment), suppression of the aerial infection process (for example, by reducing the duration of wetness in greenhouses by heating or ventilation), spraying of the foliage, as is common with foliar pathogens, in addition to preplanting treatments such as sanitation and soil disinfestation.

\section{ACKNOWLEDGMENTS}

This work was partially funded by the Chief Scientist of the Ministry of Agriculture, Israel. We thank H. Voet for helping with the statistic analyses, S. Erez, S. Lourie, S. Ben-David, and O. Ziv for technical assistance, A. Gamliel and E. Zamski for valuable suggestions, N. Dudai for providing basil seeds, and A. Maduel for his cooperation in the field experiments.

\section{LITERATURE CITED}

1. Blanchard, D., Lecoq, H., and Pitrat, M. 1994. A Colour Atlas of Cucurbit Diseases. Manson Publishing, London.

2. Davies, R. R., and Isaac, I. 1958. Dissemination of Verticillium alboatrum through the atmosphere. Nature 181:649.

3. Fletcher, J. T. 1984. Diseases of Greenhouse Plants. Longman Scientific 
and Technical, London.

4. Gamliel, A., and Katan, J. 1991. Involvement of fluorescent pseudomonads and other microorganisms in increased growth response of plants in solarized soils. Phytopathology 81:494-502.

5. Gamliel, A., Katan, T., Yunis, H., and Katan, J. 1996. Fusarium wilt and crown rot of sweet basil: Involvement of soilborne and airborne inoculum. Phytopathology 86:56-62.

6. Hartman, J. R., and Fletcher, J. T. 1991. Fusarium crown and root rot of tomatoes in the UK. Plant Pathol. 40:85-90.

7. Howard, R. J. 1958. Local and long-distance spread of Verticillium species causing wilt of alfalfa. Can. J. Plant Pathol. 7:199-202.

8. Isaac, I. 1957. Wilt of lucerne caused by species of Verticillium. Ann. Appl. Biol. 45:550-558.

9. Jarvis, W. R. 1988. Fusarium crown and root rot of tomatoes. Phytoprotection 69:49-64.

10. Katan, T., Shlevin, E., and Katan, J. 1997. Sporulation of Fusarium oxysporum f. sp. lycopersici on stem surface of tomato plants and aerial dissemination of inoculum. Phytopathology 87:712-719.

11. Katan, T., Zamir, D., Sarfatti, M., and Katan, J. 1991. Vegetative compatibility groups and subgroups in Fusarium oxysporum f. sp. radicislycopersici. Phytopathology 81:255-262.

12. McKay, M. B. 1926. Further studies of potato wilt caused by Verticillium albo-atrum. J. Agric. Res. 32:437-470.

13. Phips, P. M., and Stipes, R. J. 1976. Histopathology of mimosa infected with Fusarium oxysporum f. sp. perniciosum. Phytopathology 66:839-843.
14. Rekah, Y., Shtienberg, D., and Katan, J. 1998. Relationship between inoculum level in soil and onset of crown and root-rot disease in tomato. (Abstr.) Phytoparasitica 26:157-158.

15. Rekah, Y., Shtienberg, D., and Katan, J. 1999. Spatial distribution and temporal development of Fusarium crown and root-rot of tomato and pathogen dissemination in field soil. Phytopathology 89:831-839.

16. Roberts, F. M. 1943. Factors influencing infection of tomato by Verticillium albo-atrum. Ann. Appl. Biol. 30:327-331.

17. Rowe, R. C., and Farely, J. D. 1981. Strategies for controlling Fusarium crown and root rot in greenhouse tomatoes. Plant Dis. 65:107-112.

18. Rowe, R. C., Farely, J. D., and Coplin, D. L. 1977. Airborne spore dispersal and recolonization of steamed soil by Fusarium oxysporum in tomato greenhouses. Phytopathology 67:1513-1517.

19. Stipes, R. J., and Phipps, P. M. 1975. Fusarium oxysporum f. sp. perniciosum on Fusarium-wilted mimosa trees. Phytopathology 65:188-190.

20. Uchida, J. Y., and Kadooka, C. Y. 1996. First report of Fusarium wilt of basil in Hawaii and foliar disease initiation. Plant Dis. 80:105.

21. Vakalounakis, D. J. 1996. Root and stem rot of cucumber caused by Fusarium oxysporum f. sp. radicis-cucumerinum f. sp. nov. Plant Dis. 80:313-316.

22. Walker, J. C. 1971. Fusarium Wilt of Tomato. Monograph 6. The American Phytopathological Society, St. Paul, MN.

23. Woudt, L. P., Neuvel, A., Sikkema, A., van Grinsven, M. Q. J., de Milliano, W. A. J., Campbell, C. L., and Leslie, J. F. 1995. Genetic variation in Fusarium oxysporum from cyclamen. Phytopathology 85:1348-1355. 